\title{
Karaciğer kist hidatiğine bağlı gelişen bronkobiliyer fistül: olgu sunumu
}

\section{Bronchobiliary fistula due to hydatid disease of the liver: a case report}

Nuretdin SUNA ${ }^{1}$, Ufuk Barış KUZU1, Mahmut YÜKSEL ${ }^{1}$, Muhammet Yener AKPINAR ${ }^{1}$, Selçuk DIŞİBEYAZ , Erkan PARLAK ${ }^{2}$

Türkiye Yüksek Ihtisas Eğitim ve Araştırma Hastanesi ${ }^{1}$ Gastroenteroloji Kliniği, Ankara

Sakarya Üniversitesi Tip Fakültesi ${ }^{2}$ Gastroenteroloji Bilim Dall, Sakarya

Bronkobiliyer fistül, biliyer sistem ile bronş sistemi arasında defektif geçiş olması ile karakterize nadir görülen bir durumdur. Daha çok karaciğer kist hidatik veya amibik hastalığı, kolelitiazis, koledokolitiazis, peptik ülser, malignite, konjenital malformasyonlar ve cerrahiye sekonder bir komplikasyon olarak ortaya çıkmaktadır. Tedavisinde cerrahi yöntemlerinde, morbidite ve mortalite oranı yüksek olduğundan günümüzde daha az invaziv yöntemler tercih edilmektedir. Bu yazıda karaciğer kist hidatiğine bağlı gelişen bronkobiliyer fistüllü olgunun, endoskopik retrograd kolanjiopankreatografi yöntemi ile hem tanı konulmasinı hem de tedavi edilmesini sunuyoruz.

Anahtar kelimeler: Bronkobiliyer fistül, endoskopik retrograd kolanjiopankreatografi

\section{GİRISS}

Bronkobiliyer fistül (BBF), biliyer sistem ile bronş sistemi arasında defektif geçiş olması ile karakterize, nadir görülen bir durumdur. Genellikle karaciğer kist hidatik veya amibik hastalığı, kolelityazis, koledokolitiazis, peptik ülser, malignite, konjenital malformasyonlar ve cerrahiye sekonder bir komplikasyon olarak ortaya çıkmaktadır $(1,2)$. Klinik bulgular, altta yatan nedenden bağımsız olarak safralı öksürük (bilioptizi), ateş ve dispnedir. Bilioptizi, genellikle daima BBF açısından patognomoniktir (3). Kist diyafragmayı geçtiği zaman plevral kaviteye, intratorasik büyük vasküler yapılara, perikardiuma ve pulmoner parankime rüptüre olabilmektedir (4). Ancak kist hidatiğin toraks içine rüptürü nadir bir komplikasyondur ve karaciğer kist hidatik olgularının \%0.6 ile \%16'sında gelişmektedir (5). Karaciğer kist hidatiğin plevral boşluğa veya bronşa açılması yüksek mortalite ve morbiditeye neden olmaktadır (4). Bu yazıda karaciğer kist hidatiğine bağlı gelişen BBF'lü olgunun, endoskopik retrograd kolanjiopankreatografi (ERKP) yöntemi ile hem tanı konulmasını hem de tedavi edilmesini sunuyoruz.

\section{OLGU}

Seksensekiz yaşında kadın hasta pnömoni nedeniyle takip edilen merkezde karaciğerde kistik lezyon saptanması üzerine kliniğimize refere edildi. Öksürük ve yeşilimsi sarı renkte balgam yakınması olan hastanın özgeçmişinde aterosklero-
Bronchobiliary fistula is a rare condition characterized by an abnormal connection between the biliary and bronchial system. The condition can be caused by hydatid cysts, amoebic disease, cholelithiasis, choledocholithiasis, peptic ulcer, malignancies, congenital malformations and surgery. The risk of morbidity and mortality inherent with surgical intervention makes less invasive methods preferred. Herein, we report a case in which endoscopic retrogradcholangio pancreatography was used for the diagnosis and treatment of a bronchobiliary fistula.

Key words: Bronchobiliary fistula, endoscopic retrograde cholangiopancreatogaphy

tik kalp hastalığı mevcuttu. Fizik muayenesinde akciğerin sağ orta ve alt zonlarinda solunum seslerinde hafif azalma ve kaba raller, abdomenin sağ üst kadranında hassasiyet ve hepatomegali mevcuttu. Laboratuvar incelemesinde; aspartat aminotransferaz $18 \mathrm{U} / \mathrm{l}(<40)$, alanin aminotransferaz $12 \mathrm{U} / \mathrm{L}$ (<41), gama glutamil transferaz 24 U/L (8-61), alkalen fosfataz $78 \mathrm{U} / \mathrm{L}$ ( 40-130), total bilirubin $0.6 \mathrm{mg} / \mathrm{dl}(<1.2)$, direkt bilirubin $0.22 \mathrm{mg} / \mathrm{dl}(<0.30)$, albumin 3,03 g/dL (3.5-5.2),

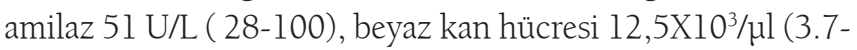
9.7), C-reaktif protein $32 \mathrm{mg} / \mathrm{dl}(0-8)$, eritrosit sedimentasyon hizı $43 \mathrm{~mm} / \mathrm{saat}(0-15)$ saptandı.

Transabdominal ultrasonografide karaciğer segment 7'de 71x60 mm çapında membranları çökmüş, diafragman bütünlüğü bozan, diaframı geçip akciğer parankimine yapışık gibi görünen kist hidatik ile uyumlu lezyon izlendi (Resim 1). ERKP'de koledok selektif kanülize edilerek sfinkterotomi yapıldı. Kolanjiogramda sağ anterior safra yollarından kist içine kaçak ve BBF traktı izlendi (Resim 2). Kiste uzanan dal içine 7 Fr nasobiliyer dren (NBD) konuldu (Resim 3). Yaşı ve komorbit durumu dikkate alınarak cerrahi girişim için yüksek riskli kabul edildi. Kliniği ve laboratuvar değerleri düzelmeye başlayan hasta NBD ile taburcu edildi. Birbuçuk ay sonra semptomları ve laboratuvar değerleri tamamen düzeldi. NBD’i çekildi. NBD çekilmesinden sonraki 18 aylık izlemde hastada semptom gelişmedi. 


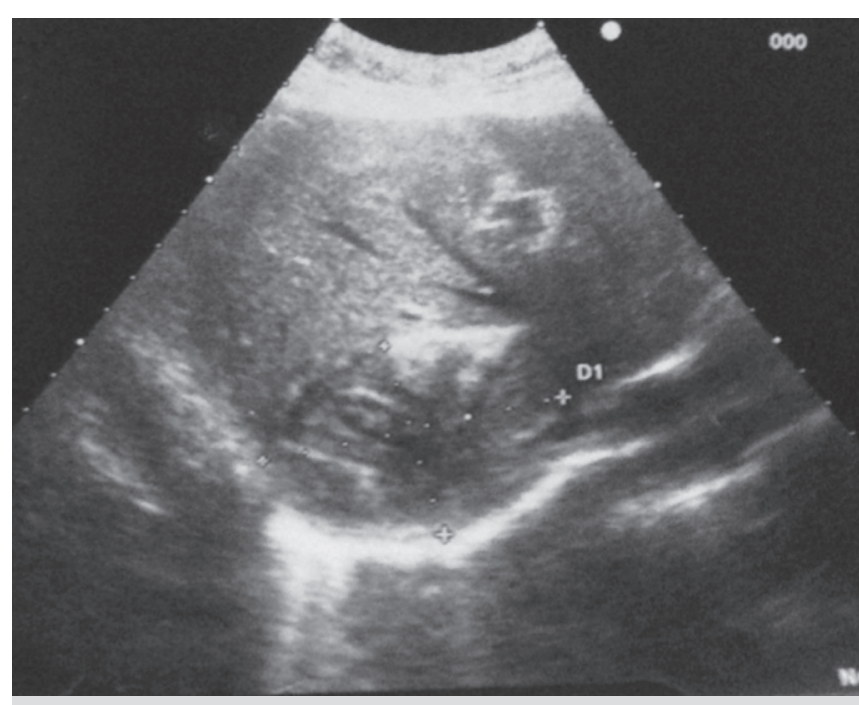

Resim 1. Transabdominal ultrasonografide karaciğer segment 7'de 7lx60 $\mathrm{mm}$ hidatik ile uyumlu lezyon.

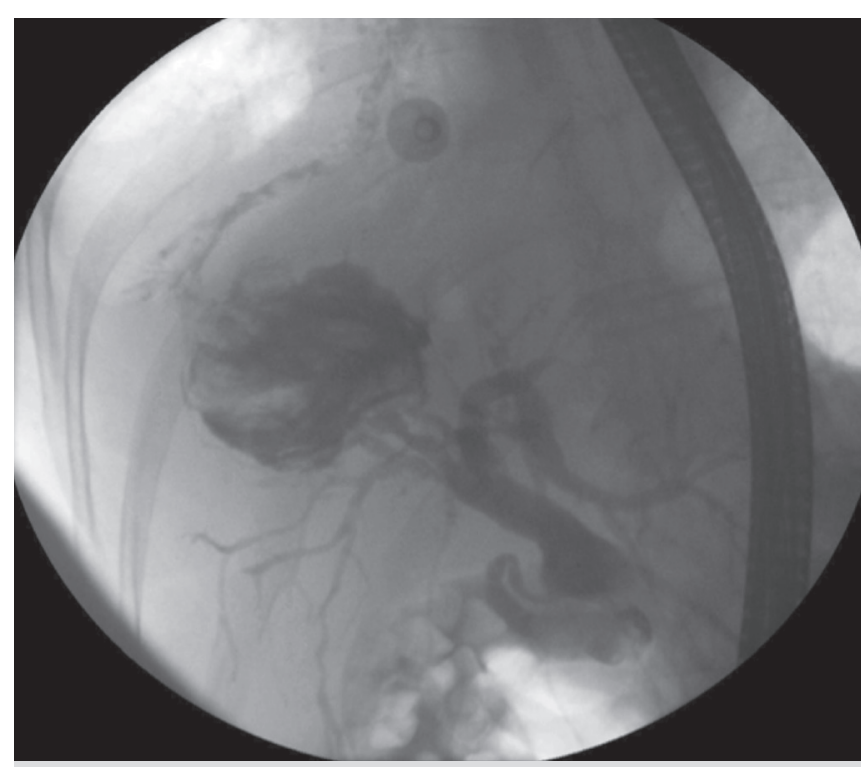

Resim 2. Endoskopik retrograd kolanjiopankreatografide sağ anterior safra yollarından kist içine kaçak ve bronkobiliyer fistül traktının görünümü.

\section{TARTIŞMA}

BBF ilk olarak Peacock tarafından 1950 yllında rapor edilmiştir (6). BBF'ün en sık sebepleri, gelişmekte olan ülkelerde karaciğer kist hidatik veya amibik hastalığı iken, batı ülkelerinde ise travma ve geçirilmiş biliyer cerrahiye sekonder gelişen komplikasyondur (1,3). Ancak 1980 ve 2010 yılları

\section{KAYNAKLAR}

1. Andalkar L, Trow TK, Motroni B, Katz DS. Bro nchobiliary fistula as a complication of liver metastases: diagnosis by HIDA scan. Clin Nucl Med 2004;29:289 -91.

2. Khandelwal M, Inverso N, Conter R, Campbell D. Endoscopic management of a bronchobiliary fistula. J Clin Gastroenterol 1996;23:125-7.

3. Kaido T, Kano M, Suzaki S et al. Bronchobiliary fistula after hepatectomy for hepatocellular carcinoma. Dig Dis Sci 2006;51:1117-21.

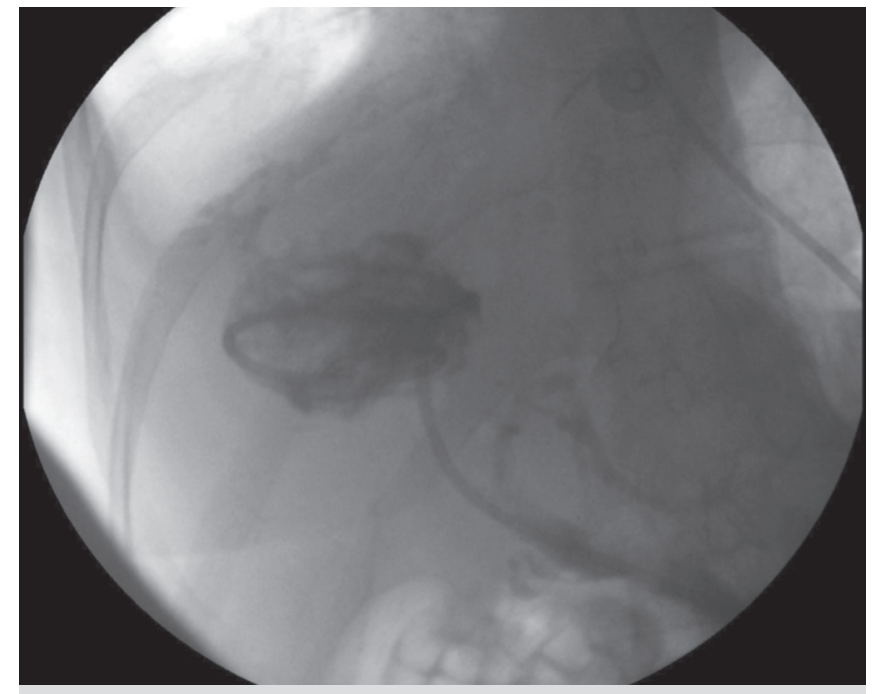

Resim 3. Kiste uzanan safra dalı içine konulan 7 Fr nasobiliyer dren izleniyor.

arasında raporlanmış olan ve toplam 68 vakadan oluşan bir derlemede, BBF'ün en sık nedeni \%32.3 oranında tümörler olduğu bildirilmiştir (7). Olgumuzda olduğu gibi genellikle tüm olgularda bilioptizi mevcuttur. Safra tahrişine sekonder pnömoniler sıklıkla görülmektedir. Bakteriyel süperenfeksiyonların da üzerine binmesiyle pulmoner komplikasyonlar mortal seyredebilmektedir (1).

BBF tanısı için ERKP veya perkütan transhepatik kolanjiografi (PTK) en çok kullanılan yöntemlerdir. Ancak, manyetik rezonans kolanjio ve hepatobiliyer iminodiasetik asit sintigrafisi gibi noninvaziv yöntemlerle de kesin tanı sağlanmaktadır. ERKP veya PTK, BBF'lerin tanısında olduğu gibi tedavisinde de kullanımaktadır. ERKP daha yaygın kullanılmaktadır (7-12). Son birkaç yıl içinde, bronkoskopi eşliğinde N-bütil siyanoakrilat embolizasyonunu ve endoskopik yol ile radyofrekans ablasyonu gibi yeni tedavi yöntemleri rapor edilmiştir. Ancak, bu yöntemlerin etkinliği tartışmalıdır (13-15). Literatürde BBF'ün tedavisi için cerrahi yöntemler öneren pek çok rapor bulunmaktadır. Ancak, cerrahi girişimlerde morbidite ve mortalite oranları yüksektir (16). Bu nedenle günümüzde cerrahi yöntemler, daha az invaziv olan diğer girişimsel teknikler başarısız olduğunda kullanılmaktadır.

Olgumuz ve literatür ışığında düşüncemiz, bronkobiliyer fistül düşünülen olgularda ERKP hem tanıda ve hem de tedavide etkili bir yöntemdir.

4. Gerazounis M, Athanassiadi K, Metaxas E, et al. Bronchobiliary fistulae due to echinococcosis. Eur J Cardiothorac Surg 2002;22:306-8.

5. Kabiri EH, El Maslout A, Benosman A. Thoracic rupture of hepatic hydatidosis (123 cases). Ann Thorac Surg 2001;72:1883-6.

6. Peacock TB. Case in which hydatids were expectorated and one of suppuration of a hydatid cyst of the liver communicating with the lungs. Edinburgh Med Surg J 1850;74:33-46. 
7. Liao GQ, Wang H, Zhu GY, et al. Management of acquired bronchobiliary fistula: A systematic literature review of 68 cases published in 30 years World J Gastroenterol 2011;17: 3842-9.

8. Karabulut N, Cakmak V, Kiter G. Confident diagnosis of bronchobiliary fistula using contrast-enhanced magnetic resonance cholangiography. Korean J Radiol 2010;11:493-6.

9. Annovazzi A, Viceconte G, Romano L, et al. Detection of a suspected bronchobiliary fistula by hepatobi-liary scintigraphy. Ann Nucl Med 2008;22:641-3.

10. D'Altorio RA, Mcallister JD, Sestric GB, Cichon PJ. Hepatopulmonary fistula: Treatment with biliary metallic endoprothesis. Am J Gastroenterol 1992;87:784-6.

11. Bird R, Fagen K, Taysom D, Silverman ED. A case of bronchobiliary fistula in the setting of adult polycystic kidney and liver disease, with a review of the literature. Clin Nucl Med 2005;30:326-8.
12. Brem H, Gibbons GD, Cobb G, et al. The use of endoscopy to treat bronchobiliary fistula caused by choledocholithiasis. Gastroenterology 1990;98:490-2.

13. Goldman SY, Greben CR, Setton A, et al. Bronchobiliary fistula success $\neg$ fully treated with n-butyl cyanoacrylate via a bronchial ap $\neg$ proach. J Vasc Interv Radiol 2007;18:151-5.

14. Kim JH, Kim MD, Lee YK, et al. Bronchobiliary fistula treated with histoacryl embolization under bronchoscopic guidance: A case report. Respiratory Medicine CME 2008;1:164-8.

15. Tran T, Hampel H, Qureshi WA, Shaib Y. Successful endoscopic management of bronchobiliary fistula due to radiofrequency ablation. Dig Dis Sci 2007;52:3178-80.

16. Rose DM, Rose AT, Chapman WC, et al. Management of bronchobiliary fistula as a late complication of hepatic resection. Am Surg 1998;64:873-6. 